\title{
Examining the Deliquescence of Lithium Salts and Those of Other Alkali Metals Through a Range of Humidity
}

Charles Allen

Andrew Ivanescu

Justus Lee

Margaret Iwu

Jaylin Brown

Katelynn Carolin

Saim Abbasi

Shane Kowaleski

Hussein Hijazi

Coryn Le

Mena Morcos

Mark Benvenuto

\section{Abstract}

It is well known that lithium chloride is able to extract moisture from the ambient air. Our research in this area has examined a variety of lithium salts for their ability to do so, as well as their counterparts containing sodium and potassium. Additionally, we have made and utilized chambers that allow us to examine deliquescence of these salts in conditions of various humidity. We will present the results, and how these experiments can be adapted to the teaching of laboratory courses.

Keywords: deliquescence, lithium salts, alkali metals, humidity

\section{Introduction}

The use of lithium chloride as a means to control the humidity of air in some commercial buildings is a well-established practice;( Fumo and Goswami, 2002) and numerous lithium-chloride-based dessicant packages are commercially available. As well, in some semi-tropical and tropical climates, a few grains of rice are often added to salt shakers to keep the salt dry and easy to pour, as a common practice, because 
even sodium chloride can extract moisture from the ambient air in humid environments. And yet the examination of deliquescence, while it has a relatively long history, (Steinbach, 1943) does not appear to have been brought into the classroom or the teaching lab in any meaningful way. Most studies of the deliquescent nature of a material appear to be focused on a specific material, or on some application of the property.( Tereschenko, 2015; Salameh and Taylor, 2006; Hiatt et al., 2011; Kallenberger and Froeba, 2018)

Our own recent work has been centered on a comparison between the deliquescent properties of several lithium salts, and their sodium counterparts, as well as their potassium counterparts, to determine which takes up more water from the surrounding air under the same conditions.( Mather et al., 2020) Table 1 shows a summary of the salts used.

Table 1: Salts used to extract moisture from air

\begin{tabular}{|l|l|}
\hline Salt & Comment, or common use \\
\hline $\mathrm{LiCl}$ & $\begin{array}{l}\text { Used as a pharmaceutical to administer lithium to the body; used as an } \\
\text { industrial dessicant. }\end{array}$ \\
\hline $\mathrm{LiNO}_{3}$ & Produces red colors in fireworks. \\
\hline $\mathrm{Li}_{2} \mathrm{SO}_{4}$ & Used as a pharmaceutical to administer lithium ion to the body. \\
\hline $\mathrm{NaCl}$ & Produced on a massive scale; in these experiments, food grade can be used. \\
\hline $\mathrm{NaNO}_{3}$ & Finds use as a food additive, number E251. \\
\hline $\mathrm{Na}_{2} \mathrm{SO}_{4}$ & Used as a filler in laundry detergents; used in paper production \\
\hline $\mathrm{KCl}_{\mathrm{KNO}}$ & A major component in "no salt": dietary supplements \\
\hline $\mathrm{K}_{2} \mathrm{SO}_{4}$ & Component of traditional gun-powders, used in fertilizers \\
\hline
\end{tabular}

As can be seen from Table 1, several of these salts have some use that impacts the general public, although such uses may not be widely known. The use of lithium salts to treat bi-polar disorder, for example, has been studied for decades, at this point.( O'Connell et al., 1991) Similarly, common table salt as well as sodium sulfate, potassium sulfate, and potassium nitrate, are produced on massive scales each year.

\section{Discussion}

An extremely simple experiment, one suitable for early college lab classes, as well as those in secondary schools, is simply to measure amounts of lithium chloride and other salts, place them in pre-weighed containers, and allow them to sit, open to the surrounding atmosphere for some amount of time. In many environments, within one hour some change in the mass of the salts occurs, routinely an increase in the mass. But the salts can also be allowed to sit for longer periods. Students can take measurements of changes in mass over the course of a day, week, or even a semester, if the instructor chooses to extend the observations for this long a period of time. Graphs can be made of the changes in mass of each material over the course of time, allowing students practice in both data gathering and analysis. 


\section{Concentrations, Molarity and molality}

An interesting outgrowth of this straightforward set of comparisons is that both molarity and molality can be determined for each of the salts. Molarity is certainly one of the most common measures of concentration taught in general chemistry classes. Although molality is less commonly taught, the mass of the starting salt, and the mass of the material after some time has elapsed provides the mass of the water that was extracted from the air, and thus what is required to determine molality as well.

\section{Weight percentage}

Gathering the changes of mass for each salt over some period of time also allows an instructor to discuss, and to have students compute, weight percentage of water and salt in each of the samples. After looking through a number of general chemistry textbooks, it is fair to say that weight percentage is taught in less detail in general chemistry classes than molarity, although it has not vanished from the curriculum.

\section{Dry environments}

While comparing the mass of water taken up from the air by various lithium, sodium, and potassium salts over time is a useful one, and works in many environments, how can this experiment be performed in extremely dry locales? There are numerous schools, colleges, and universities that exist in or near the deserts of all six of the inhabited continents. It seems logical that the uptake of water by salts in such dry environments will be tiny, and may not be noticeable at all, simply because there is very little water in the air in such places.

To illustrate this phenomenon in a dry environment, we have found that a simple, inexpensive environmental chamber can be made using a large beaker, two small containers, and some improvised lid. The experimental steps can be listed broadly as follows, below.

\section{Experimental}

All salts were purchased from scientific supply houses such as Aldrich or Flinn Scientific, and used as purchased.

Experimental steps are:

1. Weigh some amount of a salt (lithium chloride, or one of the others listed in Table 1) and place it in a small beaker or Erlenmeyer flask.

2. Weigh some amount of water, and place it in a second small beaker or Erlenmeyer flask.

3. Place both small containers in a much larger beaker.

4. Cover the beaker with aluminum foil, plastic wrap, or other material. Tape this "lid" onto the large beaker. An example is shown in Figure 1. 
5. After an hour - although the experiment can run for more or less time - remove the two small containers, and again weigh the salt in the first, and the water in the second.

Figure 1: Simple environmental chamber for deliquescence experiments

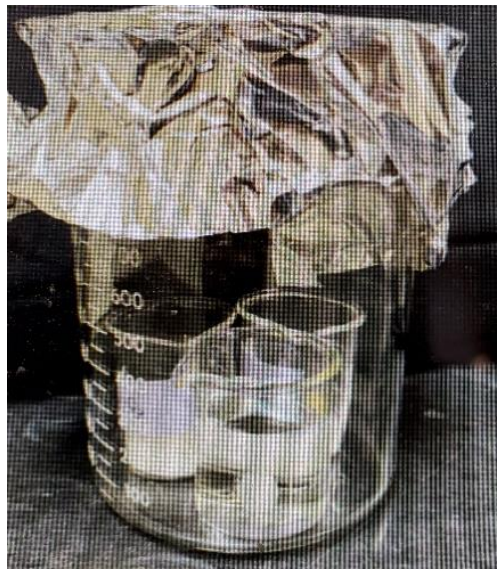

Elevating the temperature of the chamber

The use of this simple set up can be further adjusted to optimize the uptake of water by any salts in the chamber. The entire apparatus can be immersed in warm to hot water bath, often simply a large crystallizing dish or a beaker larger than the others. This can be held in place with a variety of weights, and the amount of time for which this elevated temperature experiment can be varied, as has been mentioned above, for other iterations of the experiment and comparisons.

Once again, at the conclusion of some pre-set amount of time, the inner container of salt, and the inner container of water can be weighed, providing the needed data for the just-mentioned discussion and computing of concentrations. If the instructor does not have a single container large enough to run this experiment with the nine salts listed in Table 1, perhaps obviously, several environmental chambers and warm or hot water baths can be constructed.

\section{Conclusions, educational applications, recommendations}

\section{Simplicity}

This remains a very simple experiment, but one with numerous connections to concepts taught in general chemistry classes,(NGSS; Next Generation Science Standards; Science Education for Responsible Citizenship) such as: gases, and the behavior of matter as it changes from liquid to gas, then back to liquid; concentrations of salts, as molarity, molality, or weight percent; and the phenomenon of deliquescence by a variety of ionic salts. 
Importantly, the experiments, and especially the construction of isolated environmental chambers allows for the adjustment of the environment each of the salts is in. This permits the student to maximize the uptake of water, and to make the deliquescence of salts easy and straightforward to observe.

\section{Connections to gas phase chemistry}

This set of experiments allows discussion of how water moves as a vapor. This lab therefore allows students to see, understand, and discuss the movement of some material as a gas. Since gases that are visible all tend to be toxic (such as bromine or iodine vapor), it is difficult to present experiments to students in which they can see direct or indirect evidence of a gas moving. By weighing an amount of water and an amount of salt prior to this experiment, then weighing the container of water and of salt after it has been in a controlled humidity chamber, students have direct evidence that a material - water - has moved by being transformed into a gas, then back to a liquid. It can be recommended that any discussion of gas behavior include this phenomenon.

\section{Adaptability}

We opted for the use of beakers with nothing more than aluminum foil or plastic coverings as environmentally-controlled chambers because they are simple, very inexpensive, and the easiest to adapt to any teaching lab or classroom. There are certainly other sealed containers that can be used to create a small environment in which the humidity can be adjusted and increased. But many appear to be more expensive than a beaker and plastic cover, and thus might be too expensive for some schools and school districts. One of our aims was to develop a set of experiments that is easy to adapt to virtually any classroom; and we believe this has been accomplished. It can be recommended that for teaching faculty or instructors, those introducing this to their classes for the first time, that some comparison between different means of making such chambers be presented and become part of the learning experience.

\section{References}

[1] Fumo, N. and Goswami, D.Y. (2002). Study of an aqueous lithium chloride dessicant system: air dehumidification and dessicant regeneration. Solar Energy, 72(4), 351-361.

[2] Hiatt, A.N., Feruzzi, M.G., Taylor, L.S. and Mauer, L.J. (2011). Deliquescence Behavior and Chemical Stability of Vitamin C Forms (Ascorbic Acid, Sodium Ascorbate, and Calcium Ascorbate) and Blends. International Journal of Food Properties, 14(6), 1330-1348.

[3] Kallenberger, P.A. and Froeba, M. (2018). Water harvesting from air with a hygroscopic salt in hydrogel-derived matrix. Communications Chemistry, 1(28), 1-6. 
[4] Mather, C., Cunningham, H. and Benvenuto, M. (2020). A Comparison of Ionic Compounds - Molarity, Weight Percent, and the Deliquescence of Lithium Salts. Michigan Science Teachers Association Journal, 65(1), 33-40.

[5] National curriculum in England: science programme of study. Website. (Accessed 24 February 2021, as:

www.gov.uk/government/publications/national-curriculum-in-englandscience-programmes-of-study).

[6] Next Generation Science Standards. Website. (Accessed 24 February 2021, as: nextgenscience.org).

[7] O'Connell, R.A., Mayo, J.A., Flatow, L., Cuthbertson, B., and O’Brien, B.E. (1991). Outcome of Bipolar Disorder on Long-Term Treatment with Lithium. British Journal of Psychiatry, 159, 123-129.

[8] Salameh, A.K. and Taylor, L.S. (2006). Role of Deliquescence Lowering in Enhancing Chemical Reactivity in Physical Mixtures. Journal of Physical Chemistry, B, 110(20), 10190-10196.

[9] Science Education for Responsible Citizenship. Website. (Accessed 24 February 2021, as:

ec.europa.eu/research/swafs/pdf/pub_science_education/KI-NA-26-893EN-N.pdf).

[10] Steinbach, O.F. (1943). Laboratory experiment on deliquescence and efflorescence. Journal of Chemical Education, 20(3), 146.

[11] Tereschenko, A.G. (2015). Deliquescence: Hygroscopicity of Water-Soluble Crystalline Solids. Journal of Pharmaceutical Sciences, 104(11), 3639-3652. 